\title{
Proactive Effects in Pigeons' Memory for Event Duration: Evidence for Analogical Retention
}

\author{
Marcia L. Spetch and Smit S. Sinha \\ University of Alberta, Edmonton, Alberta, Canada
}

\begin{abstract}
An intratrial proactive interference design was used to examine the nature of pigeons' memory for duration in a delayed matching task. Short ( $2 \mathrm{~s})$ or long (10 s) target samples were preceded on test trials by a short or long presample. The durations were consistent on some trials (shortshort or long-long) and inconsistent on others (short-long or long-short). Contrary to predictions based on prospective or categorical coding, accuracy was not related to duration consistency. Instead, accuracy was reduced on short-short and long-short trials and somewhat enhanced on short-long and long-long trials, suggesting that the pigeons "summed across" the durations. This occurred even with a 10-s interstimulus interval (Experiment 1) and even when the presample and target sample were physically distinct (Experiment 2). These results suggest that pigeons remember event durations in an analogical and retrospective fashion.
\end{abstract}

A number of recent experiments have examined pigeons' memory for the duration of past events within delayed symbolic matching-to-sample (DSMTS) tasks (e.g., Kraemer, Mazmanian, \& Roberts, 1985; Spetch, 1987; Spetch \& Rusak, 1989; Spetch \& Wilkie, 1983). Typically, pigeons are reinforced for pecking at one stimulus (e.g., a red key) after a short (e.g., 2 s) sample presentation and at another stimulus (e.g., a green key) after a longer presentation (e.g., $10 \mathrm{~s}$ ) of the sample. Retention of the sample duration is assessed by varying the delay between the offset of the sample and presentation of the choice stimuli.

The nature of the information that pigeons retain over a delay in these tasks has been the focus of current speculation. According to one model (Spetch \& Wilkie, 1983), pigeons retain temporal information in a retrospective and analogical fashion. That is, pigeons are assumed to maintain an analogical representation of the duration of the sample over the delay in a short-term or "working" memory (Honig, 1978). The representation is further assumed to change or weaken over the course of the retention interval, resulting in a progressive shortening of the remembered sample duration. This subjective shortening model was proposed to account for the "choose short effect" (Spetch \& Wilkie, 1982) that pigeons typically display when they are tested with delays longer than the training value.

An alternative view, first discussed by Church (1980) and formalized by Kraemer et al. (1985), is that temporal information might be encoded into categorical information on a nontemporal dimension (see also Parker \& Glover, 1987). It

This research was supported by a Natural Sciences and Engineering Research Council of Canada operating grant (OGP0038861) held by M. Spetch. We wish to thank D. Grant and D. Treit for their very helpful comments. Some of these data were presented at the meeting of the Psychonomics Society, Chicago, November 1988.

Correspondence concerning this article should be addressed to $M$. Spetch, Department of Psychology, University of Alberta, Edmonton, Alberta, Canada T6G 2E9. is this categorical code, rather than an analogical representation of the sample duration, that would be retained over the delay. Kraemer et al. (1985) suggested two specific ways that pigeons might categorically code temporal information. One is in terms of a prospective code (see Roitblat, 1980). That is, at some point during or immediately after the sample presentation, the pigeons might form an anticipatory representation of the correct response or test stimulus (e.g., peck red). Aiternatively, the pigeons might encode the sample duration into a retrospective categorical code along some nontemporal dimension. In this case, the pigeons would retrospectively maintain a representation of the category to which the stimulus belonged (e.g., short or long) but not the specific temporal characteristics of the sample itself.

The assumption that categorical information derived from temporal samples is retained along a nontemporal dimension stands in contrast to the analogical view of temporal memory contained in the subjective shortening model. Although these contrasting views can each account for many of the results obtained in memory for duration experiments (see Spetch, 1987), they lead to very different predictions about how pigeons will respond to tests that use an intratrial proactive interference procedure (e.g., Grant, 1982a). In this interference procedure, which was initially studied with colors as the samples, a target (to be remembered) sample (e.g., red) is preceded on test trials by another, interfering sample (e.g., green). Two choice stimuli are then presented, one that corresponds to the interfering sample and one that corresponds to the target sample. Subjects are reinforced for responding to the latter. This procedure has been reliably found to reduce accuracy in relation to baseline trials in which only the target is presented (e.g., Grant \& Roberts, 1973; W. A. Roberts \& Grant, 1974; Zentall \& Hogan, 1977), not only when colors are the samples but also with samples of line orientation, responses, and the presence or absence of food (Grant, 1982a). In contrast, facilitation of accuracy has been observed when the target sample is preceded by another presentation of the same sample (e.g., red followed by red; Grant, 1982b; W. A. Roberts, 1972). 
We used this general intratrial proactive interference and facilitation preparation in this experiment, but with event duration as the relevant sample dimension. Pigeons were trained to make a "short choice" (e.g., peck red) after a 2-s sample presentation (S) and a "long choice" (e.g., peck green) after a 10-s sample presentation (L). On test trials, the target sample was preceded by another sample (presample) of a consistent or inconsistent duration. An outline of this basic procedure is presented in Table 1 .

The categorical coding view and the analogical view of memory make different predictions about the results of these tests. According to the categorical coding view, accuracy on test trials should depend on the consistency of the codes generated by the presample and target sample. On Trials S-S and $\mathrm{L}-\mathrm{L}$, the code for the presample would be the same as that for the target sample; its presence should only reinforce the response tendencies controlled by this code. Therefore, accuracy on these consistent-test trials should be as high as or higher than that on baseline trials. In contrast, Trials L-S and S-L would lead to the formation of two different codes that would compete in working memory, leading to decreased accuracy on these trials.

The consistency of the samples should not, however, be the primary determinant of pigeons' responses in these tests according to an analogical view of memory for duration. According to this view, presentation of the presample prior to the target sample might be expected to simply increase the remembered duration (i.e., the durations of the two samples should summate in working memory). Accordingly, pigeons would tend to overestimate the duration of the target sample on all test trials. This should lead to accurate performance when the target sample is long (S-L and $\mathrm{L}-\mathrm{L}$ trials) and to inaccurate performance when the target sample is short (S-S and $\mathrm{L}-\mathrm{S}$ ).

The primary focus of these experiments is the results of the test trials for which the categorical and analogical views make opposite predictions: the S-S and S-L trials. The categorical view predicts a facilitation of accuracy on S-S trials because of the consistency of the codes and predicts an interference effect on the S- $L$ trials because of the inconsistency of the codes. In contrast, the analogical view of memory predicts reduced accuracy on S-S trials and enhanced accuracy on the S-L trials, because the presample and target samples should summate and thereby increase the total remembered duration.

Table 1

Proactive Interference Procedure

\begin{tabular}{ccc}
\hline Trial type & $\begin{array}{c}\text { Presample } \\
\text { (in s) }\end{array}$ & $\begin{array}{c}\text { Target sample } \\
\text { (in s) }\end{array}$ \\
\hline Baseline & - & 2 \\
S & - & 10 \\
L & 2 & 2 \\
Consistent & 10 & 10 \\
S-S & & 10 \\
L-L & 2 & 2 \\
Inconsistent & 10 & \\
S-L & & \\
L-S &
\end{tabular}

Note. $\mathrm{S}=$ short sample. $\mathrm{L}=$ long sample. Dashes $=$ not applicable.
To clearly differentiate between the predictions of competition for the categorical view, and of summation for the analogical view, it was necessary to ensure that the birds could clearly detect the break between the presample and target samples and that they would have sufficient time to encode the presample before the target sample was presented. We therefore used an interstimulus interval (ISI) between the presample and the target sample that was as long or longer than the delay interval between the target sample and choice. Because of this, the pigeons had just as much time to encode the presample before the target sample was presented as they did to encode the target sample before the choice stimuli were presented. Because baseline and test trials were intermixed within each test session, there was no way for the pigeons to determine whether the first sample presented was a target sample or a presample. Thus, if the pigeons normally retain a categorical code of the target sample over the delay interval, they should also retain a categorical code of the presample over the ISI.

In Experiment 1, we also included two test phases in which both the ISI and the delay were quite lengthy ( $5 s$ in Phase 2 and $10 \mathrm{~s}$ in Phase 3). Because these ISIs were spent in complete darkness, it seemed very unlikely that the pigeons would fail to detect the break between the two presentations of houselight. With these lengthy ISIs, it would also be difficult to argue that the pigeons did not have sufficient time to form a categorical code of the presample stimulus.

Another strategy for ensuring that the pigeons would detect the break between the presample and target samples was included in the design of Experiment 2. In this experiment, the presample and target samples were physically different stimuli. It seemed unlikely that the pigeons would fail to detect the offset of one stimulus and then, after an ISI, the onset of a different stimulus.

\section{Experiment 1}

In this experiment, illumination of a houselight served as both the target samples and the presamples. Using the basic design outlined in Table 1, we examined the effect of presample presentations in three phases that differed in terms of the ISI between the presample and target samples, as well as the delay between the target sample and choice opportunity. In the first phase, the ISI was $2 \mathrm{~s}$ and the delay was $0 \mathrm{~s}$; in the second phase both the ISI and the delay were $5 \mathrm{~s}$, and in the third phase both were $10 \mathrm{~s}$.

\section{Method}

\section{Subjects}

The subjects were 4 experimentally naive White King pigeons, between 6 months and 1 year of age. Mixed grain obtained primarily during experimental sessions maintained the pigeons at $85 \%$ to $90 \%$ of their free-feeding weights. The birds were housed in individual wire mesh cages with water and grit freely available. The colony was maintained under a $12 \mathrm{hr}$ light/dark cycle (lights on at 6:00 a.m.). 


\section{Apparatus}

The experimental chambers consisted of rectangular BRS/LVE, Inc., animal chests that contained two horizontally aligned circular response keys, each $2.5 \mathrm{~cm}$ in diameter. The keys could be transilluminated with red or green light by stimulus projectors mounted behind each key. The grain feeder was centered between and approximately $10 \mathrm{~cm}$ below the two keys, and grain presentations were accompanied by illumination of a lamp in the feeder. The houselight was a 1.6 candlepower lamp located at the top of the response panel. An exhaust fan ventilated the chamber and provided masking noise. Experimental contingencies and data recording were controlled by a microcomputer located in an adjacent room.

\section{Procedure}

Preliminary training. All birds received one or two sessions of magazine training, followed by a few sessions of autoshaping in which individual illumination of the side keys with red or green light was paired with grain presentation. This procedure continued until the birds reliably pecked the side keys when illuminated with either red or green light (between two and four sessions).

Basic DSMTS procedure. The following features of the DSMTS procedure used were common to all phases of the experiment. Trials began with presentation of the houselight as the sample stimulus. On a random half of the trials, the sample was long (10 s). On the remaining trials the sample was short $(2 \mathrm{~s})$. Termination of the sample was followed by presentation of red and green lights on the side keys as choice stimuli. One color was designated correct for short samples, the other correct for long samples. This color designation was counterbalanced across birds, and the right-left position of red and green was counterbalanced across trials within each session. A peck to either choice stimulus resulted in termination of both stimuli. If the correct stimulus was pecked, a 5-s presentation of the illuminated feeder occurred as reinforcement. If the incorrect stimulus was pecked, the trial ended without reinforcement. Hereinafter, pecks to the stimulus designated as correct for short samples are referred to as short choices, and pecks to the stimulus correct for long samples are referred to as long choices. All trials were separated by a 45 -s intertrial interval (ITI), during which the chamber was dark. Sessions were conducted 6 or 7 days a week, and each continued until 48 trials had been completed, or for a maximum of $60 \mathrm{~min}$.

The experiment entailed three training phases, each followed by one or two test phases.

Phase 1a: Training with a $0-s$ delay. Each bird was trained with no programmed delay (i.e., $0 \mathrm{~s}$ ) between sample offset and presentation of the choice stimuli for 20 sessions. During this training phase, a correction procedure was used: The stimulus events were duplicated on the next trial whenever an incorrect response was made. However, accuracy levels were determined by performance on noncorrection trials only.

Phase $1 b$ : Variable delay tests. This phase consisted of five test sessions in which the baseline 0-s delay occurred on a randomly determined half of the trials of each session, and a 5- or a 10-s delay occurred equally often on the remaining trials. No correction trials occurred during this phase.

Phase 1c: Interference tests with 0-s delay and 2-s ISI. This phase involved the procedure shown in Table 1. It consisted of 10 sessions in which the baseline conditions (i.e., 0-s delay and no presample) occurred on a randomly determined half of the trials in each session. The remaining trials consisted of four equally occurring interference trials: S-S, L-L, L-S, S-L. The presample and target sample were separated by an ISI of $2 \mathrm{~s}$ and the delay was $0 \mathrm{~s}$. The correction procedure was not in effect.
Phase 2a: Training with 5-s delay. Each bird was trained with a constant 5-s delay between sample offset and presentation of the choice stimuli for 20 sessions. The correction procedure was in effect.

$P$ Pase $2 b$ : Interference tests with 5-s delay and 5-s ISI. This phase was identical to Phase 1c except that the presample and target samples were separated by a 5-s ISI, and the delay was $5 \mathrm{~s}$ on both baseline and test trials. This phase lasted for 10 sessions.

Phase 3a: Training with 10-s delay. Each bird was trained with a 10-s delay between sample offset and presentation of the choice stimuli, and with a correction procedure in effect, until accuracy stabilized. This required 15, 25, and 20 sessions for Birds 256, 257, and 264 , respectively. Bird 260 never achieved an accuracy level that was consistently above $50 \%$ for both samples, even after 40 training sessions. Consequently, this bird was dropped from the experiment.

Phase 3b: Interference tests with 10-s delay and 10-s ISI. This phase was identical to Phase Ic except that both the ISI and the delay were $10 \mathrm{~s}$. Only three subjects served in this test phase, which lasted for 10 sessions.

\section{Results}

\section{Training Accuracy}

The birds did not display any systematic tendency to make one type of choice more often than the other by the end of any of the training phases. Averaged across the last five sessions, mean accuracy on short-sample and long-sample trials, respectively, was $88.9 \%\left(S E_{M}=2.8\right)$ and $91.9 \%\left(S E_{M}\right.$ $=2.1)$ in Phase 1a, $80.1 \%\left(S E_{M}=4.7\right)$ and $76.6 \%\left(S E_{M}=\right.$ $6.5)$ in Phase $2 \mathrm{a}$, and $77.8 \%\left(S E_{M}=4.5\right)$ and $77.1 \%\left(S E_{M}=\right.$ 1.6) in Phase 3a.

\section{Variable Delay Testing}

Table 2 shows each bird's accuracy scores on short-sample and long-sample trials as a function of delay, averaged over the five test sessions of Phase $1 \mathrm{~b}$. At the 0 -s training delay, accuracy was very high and was similar on short- and longsample trials. However, at the 5- and 10-s delays, each bird was more accurate on short-sample trials than on long-sample trials. This "choose-short" tendency is consistent with the results of previous research (e.g., Spetch, 1987; Spetch \& Wilkie, 1982).

Table 2

Correct Choices (\%) on Short-Sample (S) and Long-Sample (L) Trials as a Function of Delay for Each Pigeon During Phase $1 b$ of Experiment 1

\begin{tabular}{|c|c|c|c|c|c|c|}
\hline \multirow{2}{*}{$\begin{array}{c}\text { Pigeon } \\
\text { no. }\end{array}$} & \multicolumn{2}{|c|}{ 0-s delay } & \multicolumn{2}{|c|}{ 5-s delay } & \multicolumn{2}{|c|}{ 10-s delay } \\
\hline & $\mathbf{S}$ & $\mathrm{L}$ & $\mathbf{S}$ & $\mathbf{L}$ & $\mathrm{S}$ & $\mathrm{L}$ \\
\hline $\begin{array}{l}256 \\
257 \\
260 \\
264\end{array}$ & $\begin{array}{l}95.0 \\
88.3 \\
75.0 \\
88.3\end{array}$ & $\begin{array}{l}86.7 \\
81.7 \\
81.7 \\
93.3\end{array}$ & $\begin{array}{l}63.3 \\
93.3 \\
60.0 \\
80.0\end{array}$ & $\begin{array}{l}53.3 \\
23.3 \\
53.3 \\
46.7\end{array}$ & $\begin{array}{l}70.0 \\
90.0 \\
53.3 \\
83.3\end{array}$ & $\begin{array}{l}33.3 \\
10.0 \\
40.0 \\
36.7\end{array}$ \\
\hline$M$ & 86.6 & 85.8 & 74.2 & 44.2 & 74.2 & 30.0 \\
\hline
\end{tabular}




\section{Interference Tests}

Figure 1 shows the birds' mean accuracy scores on baseline trials ( $\mathrm{L}$ and $\mathrm{S}$ ), consistent interference trials (S-S and $\mathrm{L}-\mathrm{L}$ ), and inconsistent interference trials (L-S and S-L) for each of the three interference test phases. Data for the individual subjects are shown in Table 3. The general pattern of results is similar across birds and across the three test phases. In brief, in relation to baseline trials, accuracy on the test trials with short target samples (L-S and S-S) was decreased, whereas accuracy on the test trials with long target samples (L-L and S-L) was as high as or higher than that on the long baseline trials (L). Thus, accuracy did not depend simply on the consistency of the presample and target sample durations.

The results of particular interest are those for the two types of test trials for which the analogical model and the categorical coding models make opposite predictions. These are Trials S-S and S-L. The categorical coding model predicts facilitation on S-S trials and disruption on S-L trials, whereas the analogical model predicts exactly the opposite. The three test phases with 3 or 4 subjects provided a total of 22 observations against which these opposing predictions could be tested. Of these observations, 18 were consistent with the analogical model (indicated by a superscript $a$ on Table 3), and only 3 were consistent with the categorical coding model (indicated by a superscript $b$ ). The chance-level probability of at least 18 observations being in the direction predicted by the analogical model is .002 .

Figure 2 shows the mean overall percentage of long choices as a function of presample duration for short and long target samples. Consistent with the prediction of temporal summation derived from the analogical model, there was a general tendency for long choices to increase as the presample duration increased from $0 \mathrm{~s}$ (baseline trials) to $10 \mathrm{~s}$. This tendency was most apparent on trials with a short target sample. On trials with a long target sample, the percentage of long choices was already high on baseline trials and showed a smaller increase as a function of target sample duration.

Analyses of variance (ANOVAs) confirmed that there was a significant main effect of presample duration on the percentage of long choices during each of the three phases, Phase 1 , $F(2,6)=19.1, p<.01$; Phase $2, F(2,6)=33.7, p<.001$; Phase 3, $F(2,4)=74.7, p<.001$. During each phase, there was also a significant main effect of target sample duration, Phase 1, $F(1,3)=542.4, p<.001$; Phase $2, F(1,3)=43.4, p$ $<.01$; Phase $3, F(1,2)=37.0, p<.05$, and a significant

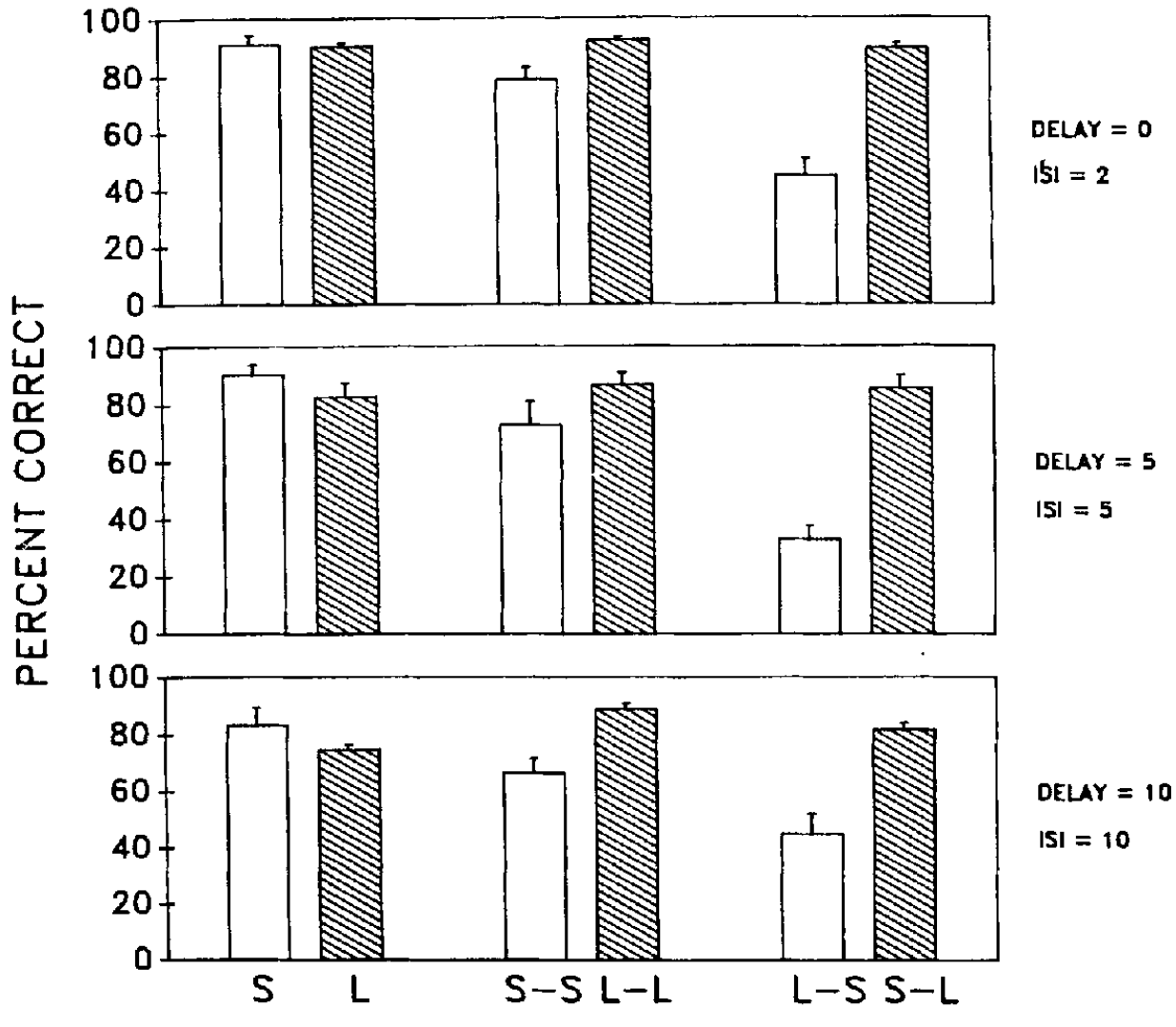

Figure 1. Mean percentage of correct choices on baseline short (S) and long (L) trials and on test trials in which the target samples were preceded by a presample of consistent duration (S-S and L-L) or inconsistent duration ( $\mathrm{L}-\mathrm{S}$ and $\mathrm{S}-\mathrm{L}$ ). (The top panel shows the results from the interference tests of Phase 1c [2-s ISI and 0-s delay], the middle panel from Phase 2b [5-s ISI and 5-s delay], and the bottom panel from Phase 3b [10-s ISI and 10-s delay] of Experiment 1. Standard errors of the mean are represented at the top of each bar.) 
Table 3

Correct Responses (\%) on Baseline and Test Trials for Each Pigeon During Three Phases of Interference Testing in Experiment 1

\begin{tabular}{|c|c|c|c|c|c|c|}
\hline \multirow{3}{*}{$\begin{array}{c}\text { Pigeon } \\
\text { no. }\end{array}$} & \multicolumn{6}{|c|}{ Trial type } \\
\hline & \multicolumn{2}{|c|}{ Baseline } & \multicolumn{2}{|c|}{ Consistent } & \multicolumn{2}{|c|}{ Inconsistent } \\
\hline & $\mathbf{S}$ & $\mathbf{L}$ & S-S & L-L & $\mathrm{L}-\mathrm{S}$ & S-L \\
\hline \multicolumn{7}{|c|}{ Test Phase 1c } \\
\hline $\begin{array}{l}256 \\
257 \\
260 \\
264\end{array}$ & $\begin{array}{l}94.2 \\
93.3 \\
81.9 \\
95.9\end{array}$ & $\begin{array}{l}87.5 \\
90.0 \\
92.9 \\
91.7\end{array}$ & $\begin{array}{l}81.7^{\mathrm{a}} \\
80.0^{\mathrm{a}} \\
66.7^{\mathrm{a}} \\
86.7^{\mathrm{a}}\end{array}$ & $\begin{array}{l}90.0 \\
95.0 \\
91.7 \\
93.4\end{array}$ & $\begin{array}{l}51.7 \\
26.7 \\
53.3 \\
48.3\end{array}$ & $\begin{array}{l}93.3^{\mathrm{a}} \\
85.0^{\mathrm{b}} \\
91.7^{\mathrm{b}} \\
88.4^{\mathrm{b}}\end{array}$ \\
\hline$M$ & 91.3 & 90.5 & 78.8 & 92.5 & 45.0 & 89.6 \\
\hline
\end{tabular}

Test Phase 2b

\begin{tabular}{lllllll}
256 & 95.9 & 90.0 & $88.3^{\mathrm{a}}$ & 90.0 & 40.0 & $93.3^{\mathrm{a}}$ \\
257 & 93.3 & 91.7 & $73.3^{\mathrm{a}}$ & 96.7 & 18.5 & $91.7^{\mathrm{a}}$ \\
260 & 80.0 & 70.8 & $50.0^{\mathbf{2}}$ & 75.0 & 35.0 & $76.7^{\mathrm{a}}$ \\
264 & 92.5 & 78.2 & $80.0^{\mathbf{2}}$ & 85.0 & 38.4 & $80.0^{\mathrm{a}}$ \\
$M$ & 90.4 & 82.7 & 72.9 & 86.7 & 33.0 & 85.4 \\
\hline
\end{tabular}

Test Phase 3b

\begin{tabular}{rrrrrrr}
256 & 95.8 & 78.3 & $76.7^{\mathrm{a}}$ & 90.0 & 58.4 & $86.7^{\mathrm{a}}$ \\
257 & 75.7 & 73.4 & $61.7^{\mathrm{a}}$ & 91.7 & 33.4 & $80.0^{\mathbf{a}}$ \\
264 & 78.4 & 72.5 & $61.7^{\mathrm{a}}$ & 85.0 & 43.3 & $78.4^{\mathbf{a}}$ \\
$M$ & 83.3 & 74.7 & 66.7 & 88.9 & 45.0 & 81.7 \\
\hline
\end{tabular}

Note. a Change from baseline in direction predicted by analogical retention. ${ }^{\mathrm{b}}$ Change from baseline in direction predicted by categorical coding. $\mathrm{S}=$ short sample. $\mathrm{L}=$ long sample.

interaction between presample and target sample duration, Phase $1, F(2,6)=36.6, p<.001$; Phase $2, F(2,6)=37.6$, $p<.004$; Phase 3, $F(2,4)=189.0, p<.001$.

\section{Discussion}

The consistency of the presample and target sample durations was clearly not the major determinant of pigeons' responses to the interference tests. Pigeons showed a disruption of accuracy on short target sample trials that were preceded by either a consistent (i.e., short) or an inconsistent (i.e., long) presample. In contrast, they generally showed some facilitation on long target sample trials preceded both by a consistent and by an inconsistent presample.

These results do not support the predictions of the categorical coding model and instead seem to support the analogical view of pigeons' memory for event duration. The overall pattern of results as well as the specific predictions from the two main types of test trials (S-S and S-L) suggest that the presence of the presample stimulus increased the remembered duration, leading to a greater tendency to make long choices.

Three specific features of this experiment are worth mentioning. First, because the pattern of results predicted by the analogical model was obtained even with a lengthy ISI (10 s), one cannot argue that summation occurred simply because the pigeons did not have sufficient time to form a categorical code of the presample duration before the target was presented. If the presample was not categorically coded by the end of the 10-s ISI, then one cannot assume that the target sample was categorically coded by the end of the delay. Nor can one argue that the ISI was so brief that the pigeons failed to notice the break between the presample and the target sample. Presumably, a 10-s period of darkness between two light presentations would provide a very salient break.

The second feature to note is that in Phase $3 b$ both the ISI and the delay were $10 \mathrm{~s}$. Thus, the presample stimuli had robust effects on choices that occurred more than $20 \mathrm{~s}$ later. Moreover, the level of this effect varied with the presample duration, as is evident in Figure 2. This implies that duration information was maintained to some degree over the 20-s interval.

Finally, it should be noted that the birds made more long choices on S-L trials than on L-S trials, even though the total duration was equal on these two types of trials (see Figure 2). Thus, the pigeons did not appear to respond to a linear sum of the two durations but to a weighted sum in which the most recent event (the target sample) was weighted more heavily than the earlier event (the presample). This unequal weighting of the two events is consistent with Staddon's (1984) model of event memory in which events are assumed to become less salient as they become more remote in time. It is also consistent with the subjective shortening model (Spetch \& Wilkie, 


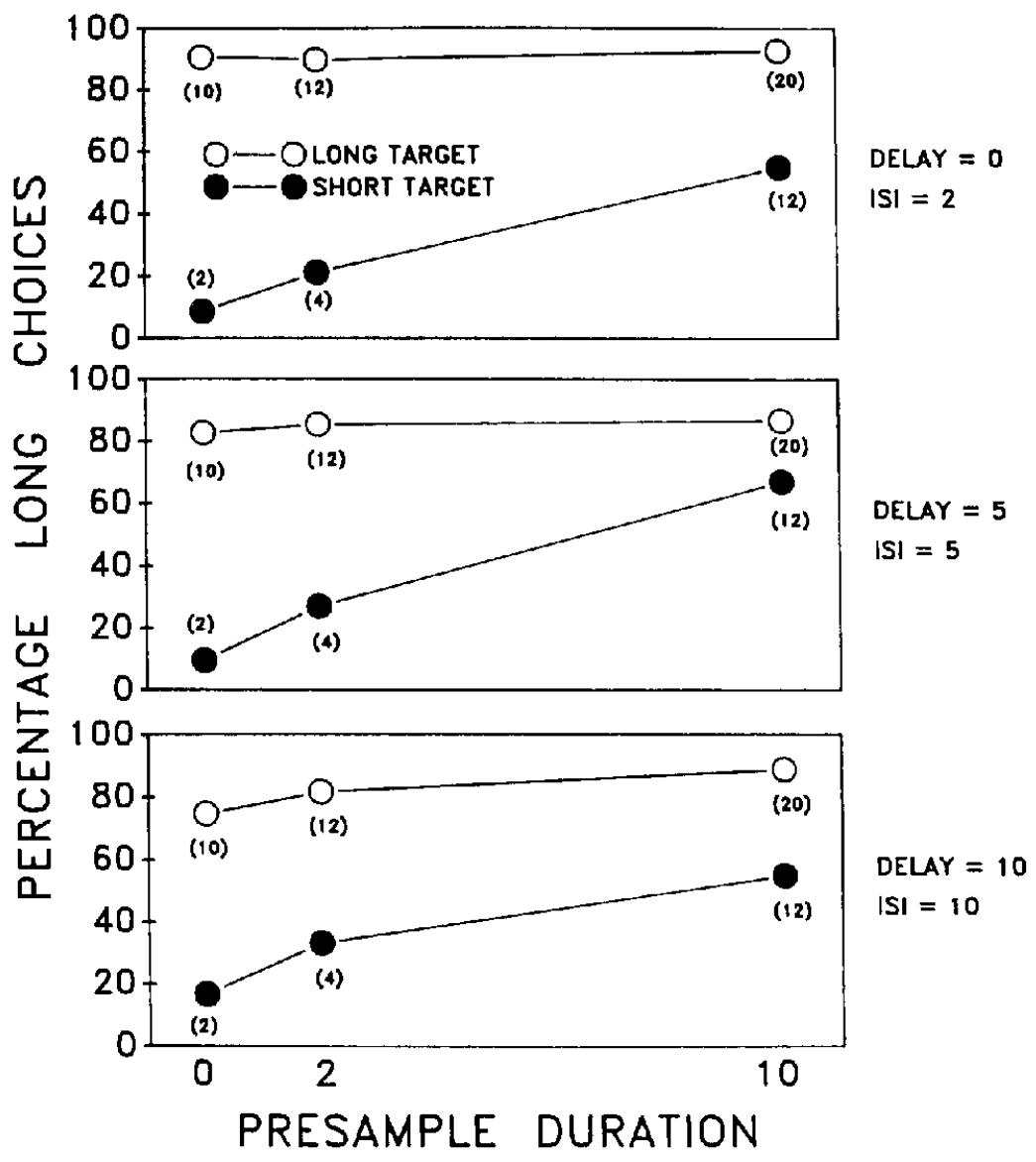

Figure 2. Mean percentage of long choices as a function of presample duration for short and long target samples during Phase $1 \mathrm{c}$ (top panel), Phase $2 \mathrm{~b}$ (middle panel), and Phase $3 \mathrm{~b}$ (bottom panel) of Experiment 1. (The numbers in parentheses beside each data point indicate the sum of the presample and target sample durations.)

1983) in which the remembered duration of an event becomes foreshortened as it recedes into the past: At the time of choice, the presample duration would have undergone more foreshortening and therefore would contribute less to the duration sum than would the target sample duration.

\section{Experiment 2}

In a DSMTS procedure, Grant (1982a) found that similar intratrial proactive interference effects occurred whether the target sample and the interfering stimulus were from the same dimension or from different dimensions. In his second experiment, for example, red pecks were reinforced after samples of food or 20 pecks, whereas green pecks are reinforced after samples of either 1 peck or no food. Accuracy was disrupted to a similar extent by the presentation of an interference stimulus from the same or different dimension. For example, when the target sample was 1 peck, the disruption of accuracy was similar for an interfering sample of food and an interfering sample of 20 pecks. These results are highly consistent with a prospective coding view of memory. That is, if both food and 20 pecks were encoded into a peck red instruction, then either one should compete with a peck green instruction to the same extent.

Grant (1982b) provided further support for this prospective coding view in a similar experiment that examined proactive facilitation effects. In his experiment, pecks to a red choice stimulus were reinforced after samples of a red key, 20 pecks, or food, and pecks to a green choice stimulus were reinforced after samples of a green key, 1 peck, or no food. On test trials the pigeons received a single sample, three successive presentations of the same sample, or the successive presentation of the three different samples that were associated with one choice stimulus (e.g., red key, 20 pecks, food). Accuracy was facilitated by multiple sample presentations, and the level of this facilitation was similar on same-sample and differentsample trials. This finding is consistent with the hypothesis that the samples generated an instructional code. The strength of this code should be enhanced to the same extent whether it is successively elicited by three different stimuli or by three presentations of the same stimulus.

Our results from Experiment 1 seem clearly inconsistent with a prospective coding view of memory. If short samples were encoded into a peck red instruction and long ones into a peck green instruction, then the presentation of a short 
presample should have produced a peck red code that would interfere with the peck green code generated by a long target sample, yet accuracy on S-L trials was often higher than on baseline trials. Similarly, presentation of a short presample should have enhanced accuracy for the short target because it would strengthen the peck red code, but accuracy was disrupted rather than facilitated on $S-S$ trials. These results suggested that our pigeons did not encode the duration samples into prospective response instructions.

Experiment 2 was designed to extend the reliability and generality of this finding. In this experiment, 4 pigeons were reinforced for pecking one color after a short ( $2 \mathrm{~s}$ ) presentation of either of two stimuli (houselight and keylight for two birds, houselight and food for the other two birds). They were reinforced for pecking another color after a long (10 s) presentation of either stimulus. During interference tests, the presample was always a different stimulus type than the target sample (as is outlined in Table 4). A replication of the results observed in Experiment 1 under these conditions will provide further support for an analogical view of pigeons' memory for event duration.

\section{Method}

\section{Subjects}

The subjects were 4 experimentally naive White King pigeons, approximately 1 year of age. They were housed and maintained as described in Experiment 1.

\section{Apparatus}

The experimental environments consisted of BRS/LVE pigeon chambers. They were similar to those used in Experiment 1 except that they contained three horizontally aligned pecking keys. The control equipment was the same as that used in Experiment 1.

Table 4

Proactive Interference Procedure for Experiment 2

\begin{tabular}{ccc}
\hline Trial type & $\begin{array}{c}\text { Presample } \\
\text { (in s) }\end{array}$ & $\begin{array}{r}\text { Target sample } \\
\text { (in s) }\end{array}$ \\
\hline Baseline & & \\
S (A) & - & $2(\mathrm{~A})$ \\
L (A) & - & $10(\mathrm{~A})$ \\
S (B) & - & $2(\mathrm{~B})$ \\
L (B) & - & 10 (B) \\
Consistent & $2(\mathrm{~B})$ & $2(\mathrm{~A})$ \\
S (B)-S (A) & $10(\mathrm{~B})$ & $10(\mathrm{~A})$ \\
L (B)-L (A) & $2(\mathrm{~A})$ & $2(\mathrm{~B})$ \\
S (A)-S (B) & $10(\mathrm{~A})$ & $10(\mathrm{~B})$ \\
L (A)-L (B) & & \\
Inconsistent & 2 (B) & $10(\mathrm{~A})$ \\
S (B)-L (A) & $10(\mathrm{~B})$ & $2(\mathrm{~A})$ \\
L (B)-S (A) & 2 (A) & $10(\mathrm{~B})$ \\
S (A)-L (B) & $10(\mathrm{~A})$ & $2(\mathrm{~B})$ \\
L (A)-S (B) &
\end{tabular}

Note. $\mathrm{A}=$ houselight samples; $\mathrm{B}=$ keylight samples for Birds 258 and 267 and food-access samples for Birds 266 and 263; $S=$ short sample. $\mathrm{L}=$ long sample. Dashes $=$ not applicable.

\section{Procedure}

Preliminary training. As in Experiment 1, all birds were first trained to eat from the grain hopper during the initial one or two sessions, and then they were given between one and four sessions with the autoshaping procedure to establish pecking to red and green stimuli on each of the side keys.

Baseline DSMTS procedure. The basic DSMTS procedure used for this experiment was the same as that used in Experiment 1 in all respects except the following. A randomly selected half of the trials in each session contained a target sample of Type A, whereas the remaining trials contained a target sample of Type B. Sample Type A was illumination of the houselight for all birds. Sample Type B was illumination of the center key with vertical stripes for Birds 258 and 267 and presentation of the illuminated food hopper for Birds 266 and 263. Pecks to one choice stimulus (red or green) were reinforced after a short presentation of either Sample A or Sample B, and pecks to the other choice stimulus were reinforced after a long presentation of either stimulus. The relationship between the specific choice stimulus and sample duration was counterbalanced across subjects.

DSMTS training. All birds were first trained on the baseline DSMTS procedure, with a correction procedure in effect and with a delay of $0 \mathrm{~s}$, until accuracy seemed stable and was well above $50 \%$ for both short and long samples of either type. Each bird then received several additional sessions with a delay of $2 \mathrm{~s}$, until accuracy was again stable. This training phase required a total of $40,50,65$, and 75 sessions for Birds 258,267, 266, and 263, respectively.

Interference testing. The procedure used during interference testing is outlined in Table 4. On a randomly selected half of the trials in each session, one of the four baseline trials occurred with equal probabilities. The remaining trials were tests in which the target sample was preceded by a presample of the other type. On a randomly selected half of these, the duration of the presample was the same as the duration of the target sample (consistent trials), whereas on the remaining trials the durations of the two stimuli were different (inconsistent trials). As in Experiment 1, reinforcement was always provided for choices appropriate to the duration of the target sample. Both the delay and the ISI were $2 \mathrm{~s}$, and there was no correction procedure during this phase. Each bird received 10 sessions of interference testing.

\section{Results and Discussions}

The overall pattern of results was highly similar to that obtained in Experiment 1. The mean accuracy scores of the 4 subjects on baseline and test trials are shown in Figure 3 for each of the two target sample types. These scores are the averages of the 10 test sessions. Table 5 shows the results for individual subjects.

As in Experiment 1, the effect of the presample stimulus depended on the duration of the target sample rather than on the consistency of presample and target sample durations. When the target sample was short, presentation of either a short or a long presample tended to disrupt accuracy, whereas when the target sample was long, a presample of either duration tended to facilitate accuracy.

Again, the specific test trials of interest are Trials S-S and $S-L$, in which the categorical coding and analogical models make opposite predictions. This experiment provided a total of 16 observations against which to test the opposing predictions. Of these, 14 were consistent with the predictions of the analogical model, and only 2 were consistent with the cate- 
TARGET SAMPLE A

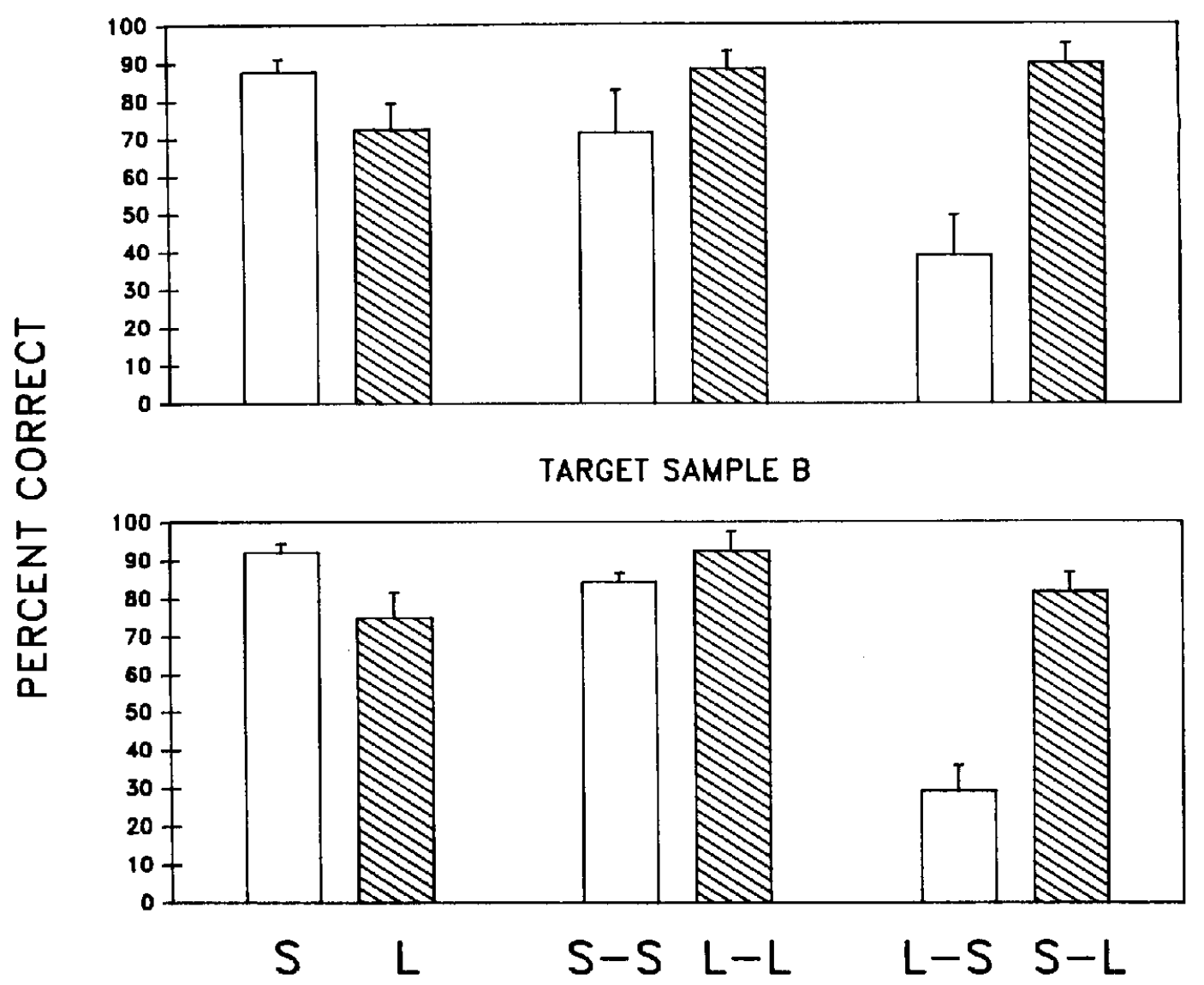

Figure 3. Mean percentage of correct choices during baseline and test trials with target sample Type A (top panel) and target sample Type B (bottom panel) in Experiment 2. (Standard errors of mean are represented at the top of each bar.)

gorical coding model. The probability of this outcome occurring by chance is .002 .

Figure 4 shows the mean percentage of long choices as a function of presample duration for each of the two target sample durations and for each of the two types of target samples. Again, there was a general increase in the percentage of long choices as a function of presample duration, and this appeared for each sample type.

A three-way ANOVA revealed a significant main effect on long choices of presample duration, $F(2,6)=106.4, p<.001$, and of target sample duration, $F(1,3)=212.0, p<.001$, but not of target sample type, $F(1,3)=0.04, p>5$. There was a significant interaction between presample and target sample duration, $F(2,6)=21.4, p<.01$, but no other significant interactions (all $p s>.1$ ).

These results extend the reliability and generality of those obtained in Experiment 1. Even when two physically different events served as the presample and target sample, pigeons showed a tendency to sum across their durations.

\section{General Discussion}

These results clearly argue against the view that pigeons encode duration stimuli into categorical information along a dimension other than time and remember this categorical code rather than the temporal properties of the sample over delay intervals (Kraemer et al., 1985; Parker \& Glover, 1987). Had the pigeons encoded the duration samples into a nontemporal category or a prospective response instruction, they should have made errors on trials with sample presentations that would generate different codes, and they should have been very accurate when two samples were presented that generated the same codes. Instead, the pigeons appeared to respond to the sum of the two presentations, which resulted in errors on short target sample trials and an increase in accuracy on long target sample trials. This finding clearly favors the view that pigeons retain an analogical memory of the temporal properties of the sample in DSMTS tasks (Spetch \& Wilkie, 1983). 
Table 5

Correct Responses (\%) on Baseline and Test Trials for Each Pigeon and for Each Type of Target Sample in Experiment 2

\begin{tabular}{|c|c|c|c|c|c|c|}
\hline \multirow{3}{*}{$\begin{array}{c}\text { Pigeon } \\
\text { no. }\end{array}$} & \multicolumn{6}{|c|}{ Trial type } \\
\hline & \multicolumn{2}{|c|}{ Baseline } & \multicolumn{2}{|c|}{ Consistent } & \multicolumn{2}{|c|}{ Inconsistent } \\
\hline & $\mathbf{S}$ & $\mathbf{L}$ & S-S & L-L & L-S & S-L \\
\hline \multicolumn{7}{|c|}{ Target Sample A } \\
\hline $\begin{array}{l}258 \\
267 \\
266 \\
263\end{array}$ & $\begin{array}{l}92.6 \\
94.2 \\
83.1 \\
80.6\end{array}$ & $\begin{array}{l}78.3 \\
89.4 \\
58.4 \\
64.3\end{array}$ & $\begin{array}{l}89.2^{\mathrm{a}} \\
87.2^{\mathrm{a}} \\
69.7^{\mathrm{a}} \\
40.9^{\mathrm{a}}\end{array}$ & $\begin{array}{c}100 \\
89.2 \\
77.7 \\
87.2\end{array}$ & $\begin{array}{l}47.4 \\
21.2 \\
65.6 \\
22.7\end{array}$ & $\begin{array}{c}100^{\mathrm{a}} \\
96.7^{\mathrm{a}} \\
79.0^{\mathrm{a}} \\
83.4^{\mathrm{a}}\end{array}$ \\
\hline$M$ & 87.7 & 72.6 & 71.8 & 88.5 & 39.2 & 89.8 \\
\hline \multicolumn{7}{|c|}{ Target Sample B } \\
\hline $\begin{array}{l}258 \\
267 \\
266 \\
263\end{array}$ & $\begin{array}{l}92.4 \\
89.0 \\
98.6 \\
88.6\end{array}$ & $\begin{array}{l}72.0 \\
58.4 \\
90.1 \\
79.9\end{array}$ & $\begin{array}{l}82.5^{\mathrm{a}} \\
79.8^{\mathrm{a}} \\
85.0^{\mathrm{a}} \\
90.7^{\mathrm{b}}\end{array}$ & $\begin{array}{c}98.0 \\
77.5 \\
100 \\
95.0\end{array}$ & $\begin{array}{l}18.4 \\
25.5 \\
24.8 \\
49.4\end{array}$ & $\begin{array}{l}82.5^{\mathrm{a}} \\
71.4^{\mathrm{a}} \\
95.0^{\mathrm{a}} \\
78.4^{\mathrm{b}}\end{array}$ \\
\hline$M$ & 92.2 & 75.1 & 84.5 & 92.6 & 29.5 & 81.9 \\
\hline
\end{tabular}

Note. $\quad{ }^{a}$ Change from baseline in direction predicted by analogical retention. ${ }^{b}$ Change from baseline in direction predicted by categorical coding.

In Experiment 1, the tests with different ISIs and different delays were included for several reasons. One reason for including tests with long ISIs (5 and $10 \mathrm{~s}$ ) was to ensure that the pigeons would have sufficient time to categorically encode the presample, should they be inclined to do so. In fact, they had as much time to encode the presample before the target sample occurred as they did to encode the target sample before the choice stimuli were presented. Moreover, with ISIs of 5 and $10 \mathrm{~s}$, we could be reasonably sure that any tendency of the pigeons to respond to the sum of the samples was not an artifact of their failing to detect the break between the two sample presentations, as could be argued if the ISIs were very brief. Finally, because we obtained very similar results at each of three delay values $(0,5$, and $10 \mathrm{~s})$, it appears that analogical retention of duration information occurs across conditions that differ considerably in terms of memory requirements.

These results are consistent with a recent experiment by Wilkie (1988) showing proactive intertrial effects in pigeons' timing behavior. In his experiment, pigeons were reinforced for pecking one color after a 2-s sample and for pecking another color after a 10-s sample. During test sessions, the ITI was decreased to $2 \mathrm{~s}$, and nonreinforced probe trials with a 6-s sample were included. The pigeons were more likely to make a long choice on these probe trials when they followed a 10-s sample trial than when they followed a 2-s sample trial. This finding clearly indicated that pigeons' timing behavior is susceptible to proactive effects but this experiment did not differentiate between an account based on categorical coding and one based on analogical memory processes. That is, the code from the preceding trial might still be present in working memory to influence choice behavior on probe trials. Alternatively, the sample duration from the preceding trial might have summated with the 6-s presentation on the probe trial, leading to more long choices when the probe followed a $10-\mathrm{s}$ trial than when it followed a 2-s trial.

Our results suggest that pigeons respond to the sum of two sample presentations, even when these are physically different events (Experiment 2). These results are consistent with the evidence suggesting that rats will sum over separate presentations of the same stimulus (S. Roberts \& Church, 1978) and also over separate presentation of two stimuli that differ in modality (S. Roberts, 1982; S. Roberts \& Church, 1978). In our experiments, however, the summation was not completely linear. Instead, the birds appeared to respond to a sum in which the target sample was weighted more heavily than the presample (the L-S trials did not generate as many long choices as the S-L trials). This asymmetry is consistent with Staddon's (1984) suggestion that remote events are less salient than recent events. It is also consistent with the subjective shortening model (Spetch \& Wilkie, 1983). According to this model, the duration of the presample stimulus would have undergone more shortening than would the duration of the target sample and consequently would contribute less to the overall remembered duration at the time of choice.

It is interesting to speculate about why pigeons might remember duration stimuli in a retrospective and analogical fashion, given that their memory for other stimulus dimensions, such as colors or lines, often seems to be prospective 

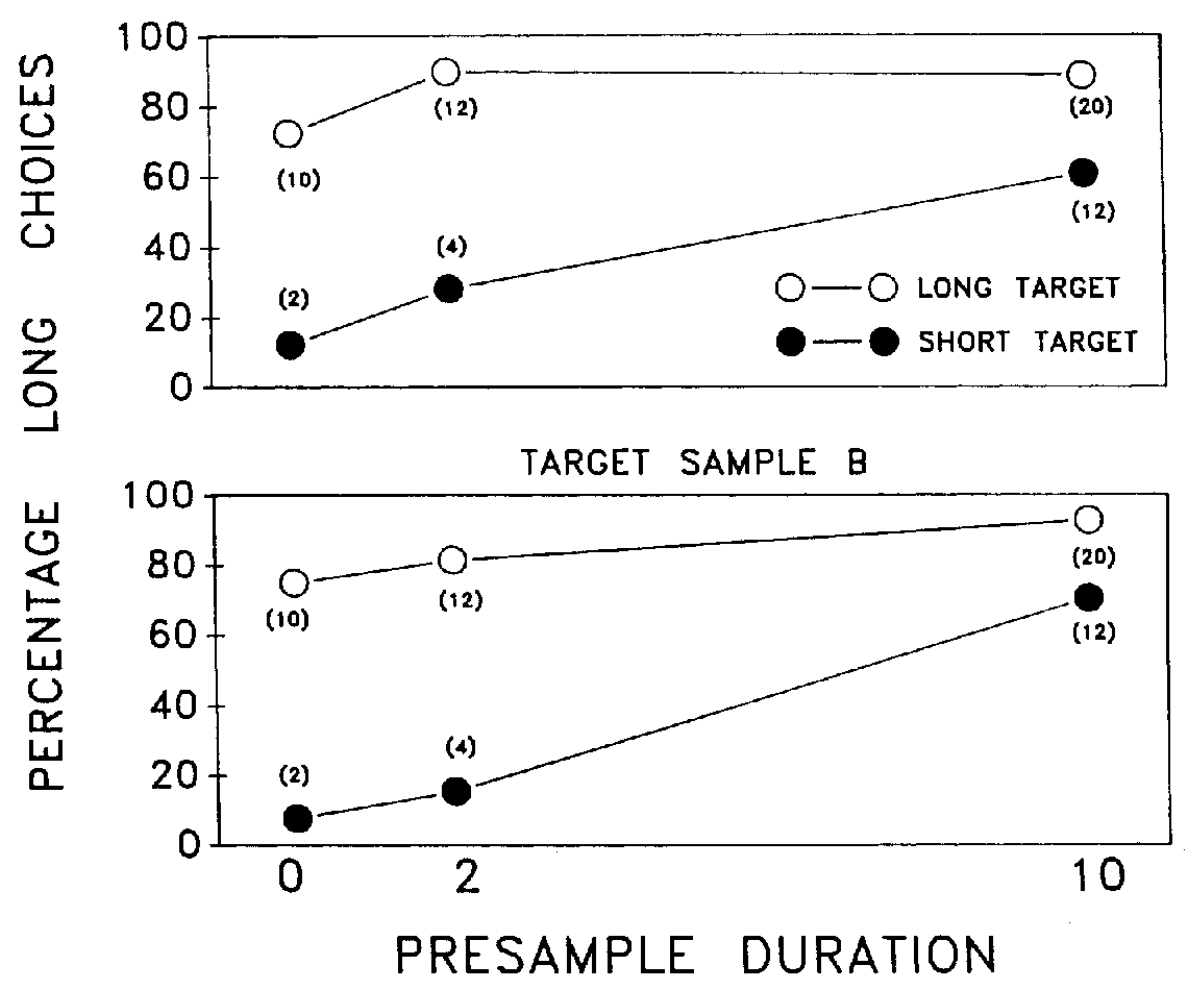

Figure 4. Mean percentage of long choices as a function of presample duration for short and long target samples and for each of the two types of target samples in Experiment 2. (The numbers in parentheses beside each data point indicate the sum of the presample and target sample durations.)

(see Wasserman, 1986, for a review; but see Urcuioli \& Zentall, 1986). The answer may lie in the nature of temporal information. With dimensions such as colors or line orientation, a prospective response instruction code could be formed as soon as the sample is presented; continued or repeated presentation of the sample would strengthen this code. However, with duration samples, the relevant information needed to form a response decision is not immediately present. Kraemer et al. (1985) suggested two general strategies that pigeons might use to encode temporal stimuli into categorical information. One is to begin with a default code and switch if it turns out to be wrong. In our view, this would be inefficient because on switch trials there should be considerable proactive interference from the incorrect default code. The segcond strategy is to form the code only after the short sample terminates or after the duration of the long sample exceeds the value of the short sample.

It may be, however, that the transient nature of temporal information makes duration samples inherently less conducive to prospective coding than samples for which a code can be formed immediately. The necessity of reserving judgment for at least a portion of the sample presentation might encourage the pigeon to withhold its response decision and retain the temporal information in an analogical form until the time of choice.

\section{References}

Church, R. M. (1980). Short-term memory for time intervals. Learning and Motivation, 11, 208-219.

Grant, D. S. (1982a). Intratrial proactive interference in pigeon shortterm memory: Manipulation of stimulus dimension and dimensional similarity. Learning and Motivation, 13, 417-433.

Grant, D. S. (1982b). Prospective versus retrospective coding of samples of stimuli, responses, and reinforcers in delayed matching with pigeons. Learning and Motivation, 13, 265-280.

Grant, D. S., \& Roberts, W. A. (1973). Trace interaction in pigeon short-term memory. Journal of Experimental Psychology, 101, 2129.

Honig, W. K. (1978). Studies of working memory in the pigeon. In S. H. Hulse, H. Fowler, \& W. K. Honig (Eds.), Cognitive processes in animal behavior (pp. 211-248). Hillsdale, NJ: Erlbaum.

Kraemer, P. J., Mazmanian, D. S., \& Roberts, W. A. (1985). The choose-short effect in pigeon memory for stimulus duration: Subjective shortening versus coding models. Animal Learning \& Behavior, 13, 349-354.

Parker, B. K., \& Glover, R. L. (1987). Event duration memory: The effects of delay-interval illumination and instructional cueing. $A n$ imal Learning and Behavior, 15, 241-248.

Roberts, S. (1982). Cross-modal use of an internal clock. Journal of Experimental Psychology: Animal Behavior Processes, 8, 2-22.

Roberts, S., \& Church, R. M. (1978). Control of an internal clock. Journal of Experimental Psychology: Animal Behavior Processes, 4, 318-337. 
Roberts, W. A. (1972). Short-term memory in the pigeon: Effects of repetition and spacing. Journal of Experimental Psychology, 94, 74-83.

Roberts, W. A., \& Grant, D. S. (1974). Short-term memory in the pigeon with presentation time precisely controlled. Learning and Motivation, 5, 393-408.

Roitblat, H. L. (1980). Codes and coding processes in pigeon shortterm memory. Animal Learning \& Behavior, 8, 341-351.

Spetch, M. L. (1987). Systematic errors in pigeons' memory for event duration: Interaction between training and test delay. Animal Learning \& Behavior, 15, 1-5.

Spetch, M. L., \& Rusak, B. (1989). Pigeons' memory for event duration: Intertrial interval and delay effects. Animal Learning \& Behavior, 17, 147-156.

Spetch, M. L., \& Wilkie, D. M. (1982). A systematic bias in pigeons' memory for food and light durations. Behaviour Analysis Letters, 2, 267-274.

Spetch, M. L., \& Wilkie, D. M. (1983). Subjective shortening: A model of pigeons' memory for event duration. Journal of Experimental Psychology: Animal Behavior Processes, 9, 14-30.
Staddon, J. E. R. (1984). Time and memory. Annals of the New York Academy of Sciences, 423, 322-334.

Urcuioli, P. J., \& Zentall, T. R. (1986). Retrospective coding in pigeons' delayed matching-to-sample. Journal of Experimental Psychology: Animal Behavior Processes, 12, 69-77.

Wasserman, E. A. (1986). Prospection and retrospection as processes of animal short-term memory. In D. F. Kendrick, M. E. Rilling, \& M. R. Denny (Eds.), Theories of animal memory (pp. 53-75). Hillsdale, NJ: Erlbaum.

Wilkie, D. M. (1988). Proactive effects in pigeons' timing behavior: Implications for an internal-clock model. Animal Learning \& Behavior, 16, 132-136.

Zentall, T. R., \& Hogan, D. E. (1977). Short-term proactive inhibition in the pigeon. Learning and Motivation, 8, 367-386.

Received August 26, 1988

Revision received March 30, 1989

Accepted April 11, 1989

\title{
Mineka Appointed Editor of Journal of Abnormal Psychology, 1990-1995
}

The Publications and Communications Board of the American Psychological Association announces the appointment of Susan Mineka, Northwestern University, as editor of the Journal of Abnormal Psychology for a 6-year term beginning in 1990. As of January 1, 1989, manuscripts should be directed to

\author{
Susan Mineka \\ Northwestern University \\ Department of Psychology \\ 102 Swift Hall \\ Evanston, Illinois 60208
}

